Научная статья

УДК 581.9

DOI 10.18101/2587-7148-2021-1-12-29

\title{
ВЫСОТНО-ЗОНАЛЬНОЕ РАСПРЕДЕЛЕНИЕ СОСУДИСТЫХ РАСТЕНИЙ РЕСУРСНОГО РЕЗЕРВАТА «ВЕРХНЕИНДИГИРСКИЙ» (РОССИЯ, СЕВЕРО-ВОСТОЧНАЯ ЯКУТИЯ)
}

\section{Е. Г. Николин}

\section{(C) Николин Евгений Георгиевич}

доктор биологических наук, главный научный сотрудник, Институт биологических проблем криолитозоны ФИЦ ЯНЦ СО РАН Россия, 677891, г. Якутск, пр. Ленина, 41 enikolin@yandex.ru

Аннотация. Ресурсный резерват республиканского значения (Республики Саха (Якутия)) «Верхнеиндигирский» расположен на территории Российской Федерации в Оймяконском нагорье, близ границы Якутии, Магаданской области и севера Хабаровского края. Высотный интервал данной местности 850-1700 м над ур. м. Флора ресурсного резервата сформирована в условиях экстремального климата северного полюса холода, что отразилось на ее особенностях. По методике конкретных флор А. И. Толмачева обследовано два участка ООПТ: в нижнем течении р. Тарын-Юрях (север резервата) и оз. Лабынгкыр (юг). Растительный покров ООПТ образует высотные пояса - лесной, подгольцово-кустарниковый, эпилитно-лишайниковый и комплекс долинной растительности. В силу особенностей физико-географического положения тундровый пояс не выражен. Подавляющее число видов (292-87\%) сосредоточено в долинном комплексе растительности. На горных склонах разнообразие флоры значительно снижается: в лесном поясе зарегистрировано 139 видов (41\%), в подгольцово-кустарниковом поясе - 47 видов (14\%), а в нижней части пояса эпилитно-лишайниковых сообществ лишь 8 видов (2\%). Распределение растений ресурсного резервата по высотным поясам соответствует таковому в системе Верхоянского хребта, примыкающей к данной местности. Однако долевое участие растений долинного комплекса по сравнению с растениями горных склонов здесь повышено и полностью отсутствует компонент тундрового пояса. Такая особенность обусловлена более суровыми природно-климатическими условиями исследованной территории.

Ключевые слова: Северо-Восточная Якутия; ресурсный резерват «Верхнеиндигирский»; оз. Лабынгкыр; высотная поясность растительности; сосудистые растения; локальная флора; вид.

\section{Для цитирования}

Николин Е. Г. Высотно-зональное распределение сосудистых растений ресурсного резервата «Верхнеиндигирский» (Россия, Северо-Восточная Якутия) // Вестник Бурятского государственного университета. Биология. География. 2021. № 1. С. 12-29.

DOI 10.18101/2587-7148-2021-1-12-29 
Е. Г. Николин. Высотно-зональное распределение сосудистых растений ресурсного резервата «Верхнеиндигирский» (Россия, Северо-Восточная Якутия)

Введение. ООПТ ресурсный резерват республиканского (Республики Саха (Якутия)) значения «Верхнеиндигирский» находится в России, на северо-востоке Якутии, близ границы Магаданской области и севера Хабаровского края. Приблизительные координаты центральной части резервата - 62 $50^{\prime}$ с.ш., $144^{\circ} 04^{\prime}$ в. д. Площадь ресурсного резервата - 4283,7 км².

Резерват «Верхнеиндигирский» расположен в пределах Оймяконского нагорья с отметками высоты от 850 до 1200 над ур. м., на юге переходящего в отроги хребта Сунтар-Хаята, с высотами до 1700 м. Водотоки резервата входят в гидрологическую сеть бассейна р. Индигирка, представляют ее истоки, наиболее значительные из которых — p. Туора-Юрях (с притоком - p. Лабынгкыр), Буор-Юрях и Тарын-Юрях. Урез воды рек превышает 850 м над ур. м. Наиболее интересными гидрологическими объектами резервата являются оз. Лабынгкыр и сеть горных озер - Ворота, Ястребиное и другие, с которыми связана легенда о проживающем здесь динозавре [7]. Урез воды в южной оконечности оз. Лабынгкыр 1000-1010 м над ур. м.

Территория резервата входит в область экстремально холодного климата северного полюса холода, где минимальные зимние температуры воздуха приближаются к отметкам $-70{ }^{\circ} \mathrm{C}$, а сплошные толщи многолетней мерзлоты достигают 400-700 м ${ }^{1}$. Такое положение существенно влияет на состав флоры и структуру растительного покрова, что проявляется в отборе наиболее устойчивых к холоду и условиям горной местности растений криофитов и соответствующих растительных сообществ.

Растительность ресурсного резервата. Территория ООПТ относится к Индигирскому округу Северо-Восточной северо-таежной подпровинции, который характеризуется преобладанием горных лесов из Larix cajanderii; в долинах рек расположены чозениевые и тополевые леса; обилен кустисто-лишайниковый покров, проявляется криофильное остепнение и влияние образования речных наледей ${ }^{2}$.

В соответствии с развитием горного рельефа растительный покров структурирован высотными поясами - лесным, подгольцово-кустарниковым, эпилитнолишайниковым поясом и комплексом долинной растительности [4; 5]. Тундровый пояс, ввиду относительно небольших высот и значительной степени обнажения горных пород на вершинах гор (в основном осыпи), практически не выражен. Горные тундры проявляются небольшими фрагментами в других поясах растительности, преимущественно в южной части резервата. Собственно степные сообщества, свойственные бассейну р. Индигирка, на территории ООПТ практически не встречаются. Остепнение южных склонов и надпойменных террас проявляется в крайне редуцированных формах, обычно сопровождается обширными обнажениями горного щебня.

Долинный комплекс растительности (рис. 1, 2). На севере резервата, где русла рек разработаны сильнее и протекают по меньшим высотам местности в долинном комплексе, кроме лиственницы, значительную роль играют древовидные ивы, то-

\footnotetext{
${ }^{1}$ Атлас сельского хозяйства Якутской АССР. М., 1989. 115 с.

2 Основные особенности растительного покрова Якутской АССР. Якутск: ЯФ СО АН CCCP, 1987. $156 \mathrm{c}$.
} 
поль и чозения. Развиты болота, заболоченные луга, ерники. На мелководьях озер формируются заросли осок, хвощей, пушиц, арктофилы, рдестов, и других водных растений. По периферии наледных полян развиваются низкорослые приналедные ивняки, ерники, тополевые и чозениевые редины, дриадовые пустоши, луга и болота. Южнее, где русла рек глубже врезаны и пролегают по большим высотам местности, роль древовидных ив, тополя и чозении снижается. Возрастают площади заболоченных ерников, болот, заболоченных лугов. Окраины озер окружены узкой полосой травянистой, с высокой долей осок, пушиц и хвощей, и древесно-кустарниковой растительности, быстро переходящей в лиственничники горных склонов.

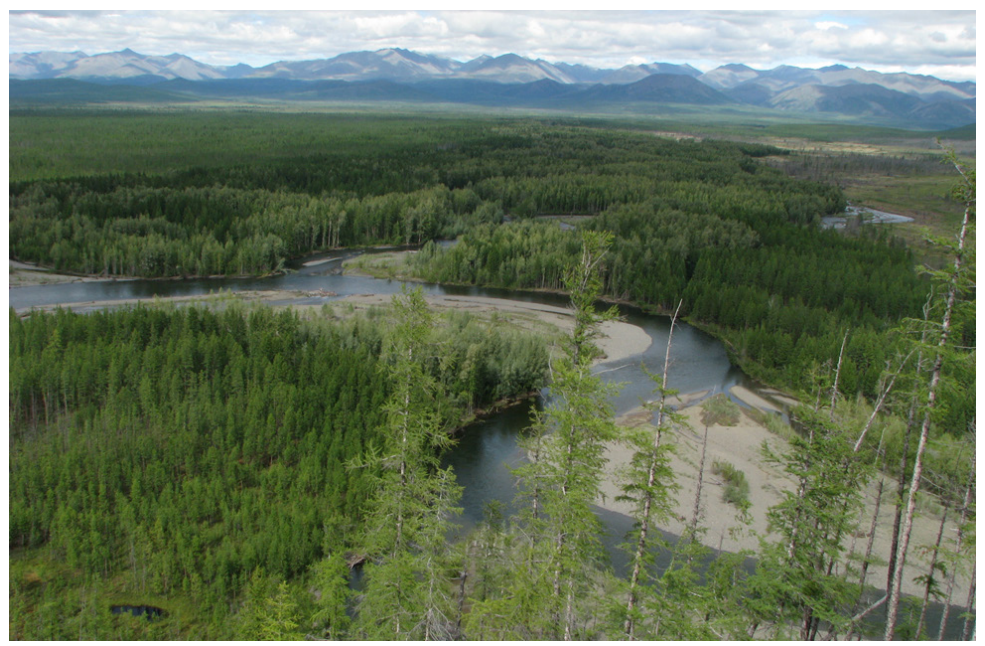

Рис. 1. Долинный комплекс растительности р. Тарын-Юрях в месте впадения правого притока - руч. Баягап

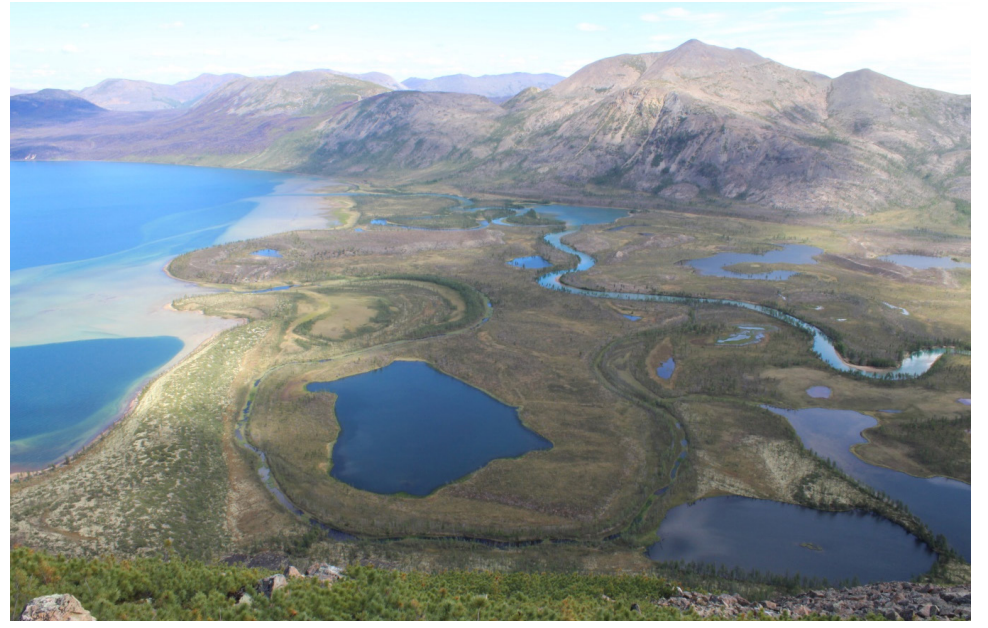

Рис. 2. Долинный комплекс растительности в южной оконечности озера Лабынгкыр (правее - одноименная река, впадающая в озеро и сеть небольших пойменных озер). Господствующая вершина на дальнем плане справа — гора Юбилейная 
Е. Г. Николин. Высотно-зональное распределение сосудистых растений ресурсного резервата «Верхнеиндигирский» (Россия, Северо-Восточная Якутия)

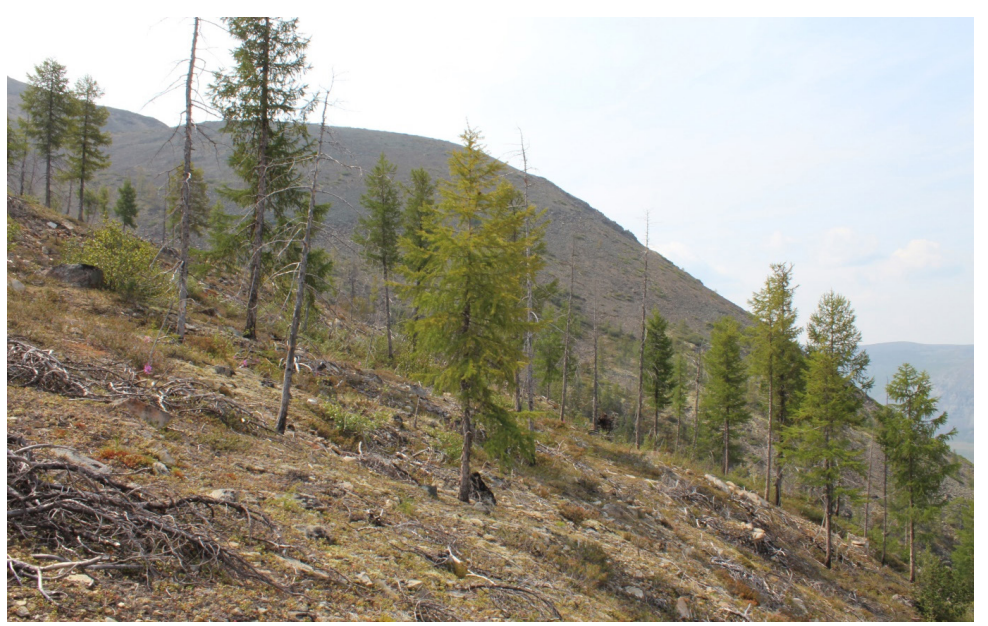

Рис. 3. Лесной пояс: лиственничное редколесье со следами старой гари на западном склоне горы Юбилейная (в юго-восточной оконечности оз. Лабынгкыр)

Лесной пояс (рис. 3) формируют лиственничные леса и редколесья с доминированием в подлеске кедрового стланика, березы растопыренной, душекии кустарниковой, каменистые, зеленомошные или лишайниковые, часто со следами лесных пожаров. На высоте более 1000 м они чередуются с относительно низкорослыми (до 1,5-2 м) зарослями кедрового стланика.

Подгольцово-кустарниковый пояс (рис. 4) расположен выше лесного пояса и выражен неравномерно, малообособленными крупными фрагментами. Здесь участки зарослей кедрового стланика перемежаются с лиственничными рединами, каменными осыпями, покрытыми эпилитными лишайниками, небольшими участками тундр с доминированием кассиопеи, дриад, багульника.

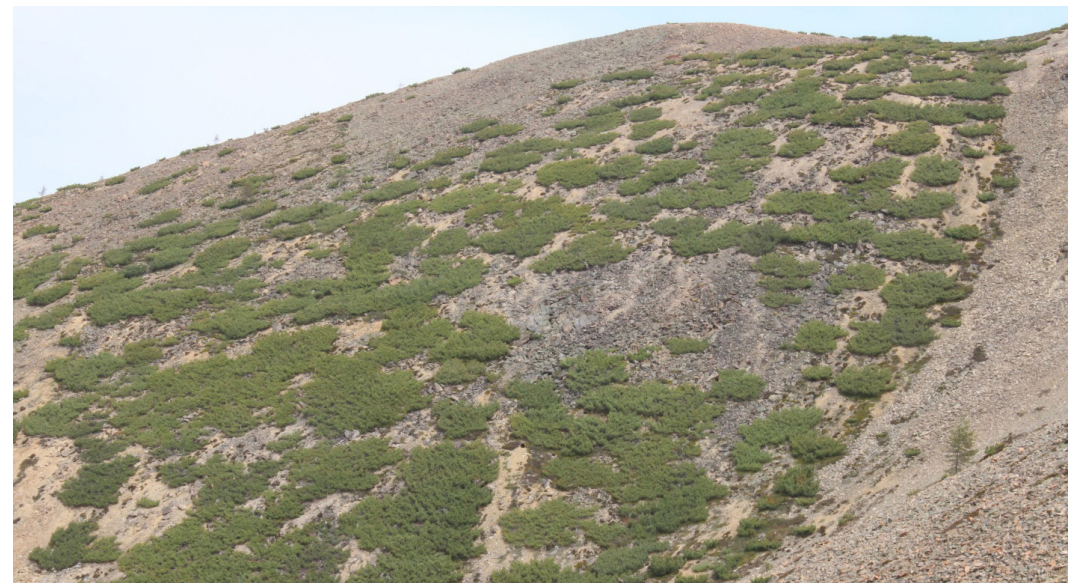

Рис. 4. Подгольцово-кустарниковый пояс: фрагмент зарослей Pinus pumila в распадке юго-западной экспозиции горы Юбилейная 
Пояс эпилитно-лишайниковых сообществ (рис. 5). На высоте более 1300-1400 м подгольцово-кустарниковый пояс переходит в пояс эпилитно-лишайниковых сообществ, в котором господствуют каменные осыпи, покрытые накипными и листоватыми эпилитными лишайниками с небольшими куртинами мхов и кустистых лишайников. Иногда в нижней части этого пояса встречаются низкие, разреженные кусты кедрового стланика, мелкие пятна или фрагменты тундр с ограниченным составом сосудистых растений.

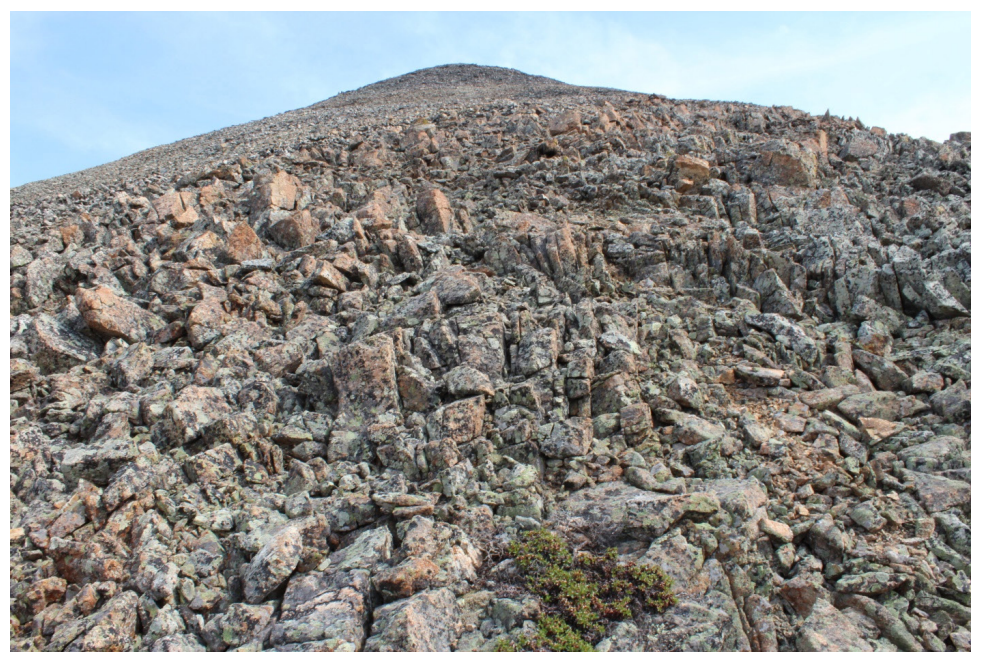

Рис. 5. Пояс эпилитно-лишайниковых сообществ: предвершинный участок западного склона горы Юбилейная (внизу, в центре - одиночная куртина Salix tschuktschorum)

Материалы и методы. Учет флоры проводился по методике А. И. Толмачева [8-10]. В объеме локальной флоры обследовано два участка местности: 1. Локальная флора «Куранах-Сала» находится в северной части ООПТ, недалеко от границы Магаданской области. Охватывает пойму р. Тарын-Юрях и примыкающие к ней левобережные возвышенности, расположенные в междуречье руч. Лагерный, руч. Баягап, р. Буор-Юрях и р. Тарын-Юрях (рис. 1). Работы проводились близ базового лагеря (пункт с координатами $63^{\circ} 05^{\prime} 54,5^{\prime \prime}$ с. ш., $144^{\circ} 366^{\prime} 47,9^{\prime \prime}$ в. Д., высота местности близ уреза воды - 855 м над ур. м.), с радиальными маршрутами от него в пределах дневных переходов (на удалении до 5-7 км). В зону обследования вошла господствующая возвышенность - безымянная вершина в левобережье р. Тарын-Юрях, с отметкой высоты 1209 м. Срок проведения работ 20 июля - 4 августа 2008 г.

2. Локальная флора «Лабынгкыр» преимущественно расположена в южной оконечности оз. Лабынгкыр (рис. 2-5), но охватывает и его северо-восточную прибрежную часть, у выхода одноименной речки из озера. Работы проводились близ базового лагеря (пункт с координатами $62^{\circ} 26^{\prime} 01,9^{\prime \prime}$ с.ш., $143^{\circ} 36^{\prime} 21,0^{\prime \prime}$ в.д., высота местности у уреза воды - 1013 м над ур. м.), с радиальными маршрутами от него, охватывающими две прилегающие господствующие вершины: гору Рептилия (вершина 1410 м над ур. м., в юго-западной оконечности озера) и гору Юбилейная (вершина 1684 м выс., в юго-восточной оконечности озера). Вершина горы Рептилия находится в пределах подгольцово-кустарникового пояса (развиты кусты кедрового 
Е. Г. Николин. Высотно-зональное распределение сосудистых растений ресурсного резервата «Верхнеиндигирский» (Россия, Северо-Восточная Якутия)

стланика и фрагменты каменистой кассиоповой тундры), а вершина горы Юбилейная - в пределах пояса эпилитно-лишайниковых сообществ (сосудистые растения отсутствуют). Работы проведены в период 26 июня -8 июля 2012 г.

Кроме этого, ограниченным флористическим обследованием охвачен крайний северо-западный участок резервата, в районе горы «Часовой», у слияния р. ТарынЮрях и Туора-Юрях. Это небольшая возвышенность в левобережье притоков Индигирки, с отметкой высоты 930 м над ур. м. Координаты пункта у подножья

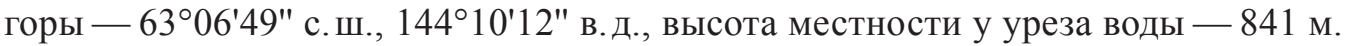
Вершина горы покрыта лиственничным лесом, склоны — каменистыми редколесьями со следами гари, каменными осыпями и незначительным проявлением элементов остепнения. Обследованием охватывались склоны горы северной и северо-восточной экспозиции, обращенные к реке. Срок проведения работ с 4 по 6 августа 2008 г.

Номенклатура растений, за редким исключением, принята в соответствии с многотомным изданием «Флора Сибири» ${ }^{1}$ и «Конспектом флоры Азиатской России»².

Результаты и обсуждение. Высотно-зональному распределению сосудистых растений горных территорий всегда уделяется особое внимание. В горах севера Евразии этому был посвящен цикл публикаций В. Б. Куваева, которые нашли логическое завершение в его монографии [1]. Оригинальный подход к изучению высотнозонального распределения растений хребта Сунтар-Хаята был у Б. А. Юрцева [11]. На основе обобщения использованной терминологии разных исследователей горной растительности и флоры нами были предложены унификация наименований высотных поясов применительно к горному ландшафту Северо-Восточной Азии [6] и обособление от высотных поясов комплекса долинной растительности (в том числе и как своеобразного парциального компонента флоры) [2; 3]. По предшествующим данным [4], общее высотно-зональное распределение сосудистых растений в системе Верхоянского хребта находится в следующем соотношении:

1. Долинный комплекс растительности - 83\% сосудистых растений (749 видов). Это наиболее специфичный компонент флоры, в котором распространено 116 видов, не заходящих на горные склоны.

2. Лесной пояс - 54\% (485) видов. В том числе только в ЛП встречается 17 видов. Данный пояс, находясь в интервале между долинной и тундровой растительностью, которые в определенном смысле проявляют тенденции к экспансии территории, оказывает значительное влияние на формирование общего состава флоры, его преимущественно лесопроизводного компонента.

3. Пояс подгольцовых кустарников - 27\% (247) видов, в числе которых лишь два не отмечались в других поясах. Можно считать, что этот пояс не имеет самостоятельного флористического значения. С одной стороны, он сильно связан с лесным поясом и по составу доминантов представляет собой верхний форпост подлеска лесной растительности. С другой стороны, с верхнего яруса гор в него заходят обычные виды, свойственные тундровой растительности.

\footnotetext{
${ }^{1}$ Флора Сибири. Новосибирск: Наука, 1987-2003. Т. 1-14.

2 Конспект флоры Азиатской России: Сосудистые растения. Новосибирск: Изд-во СО РАН, 2012. $640 \mathrm{c}$.
} 
4. Тундровый пояс - 50\% (451) видов, в числе которых 29 таксонов распространено только здесь. В тех случаях, когда тундровый пояс хорошо выражен, он оказывает существенное влияние на весь состав флоры, в том числе обогащая и нижерасположенные пояса.

5. Пояс эпилитно-лишайниковых сообществ - 6\% (53) видов. По сути, это верхний участок продвигающейся в горы растительности (в основном тундро-производной и петрофитной), который не имеет специфических видов сосудистых растений. Здесь наиболее суровые условия микроклимата и крайне примитивные почвы. Заходящие в этот пояс растения могут служить эталоном наиболее жизнестойких криофитов.

Во флоре ресурсного резервата «Верхнеиндигирский» всего выявлено 326 видов, 9 обособленных подвидов и 2 разновидности из 133 родов и 55 семейств [5]. В долинном комплексе растительности сосредоточено 87\% всей флоры ресурсного резервата - 292 вида и внутривидовых таксонов (табл.). Из этого числа 192 вида (59\%) приурочены только к долинам. Вероятно, в результате влияния частых лесных пожаров и особенностей горообразовательных процессов, препятствующих полноценному развитию горных тундр, разнообразие сосудистых растений горных склонов данной местности довольно низкое. В лесном поясе зарегистрировано $41 \%$ (139 видов, подвидов и разновидностей, в том числе только в этом поясе - 21 вид), в подгольцово-кустарниковом - 14\% (47 видов, из которых 5 отмечены только в данном поясе), а в нижней части пояса эпилитно-лишайниковых сообществ $2 \%$ (8 видов из нижерасположенных поясов).

К высотным убиквистам (видам, распространенным по всему вертикальному профилю) можно отнести лишь 4 вида - Pinus pumila, Salix tschuktschorum, Ledum palustre subsp. decumbens и Cassiope ericoides. Почти убиквистами, распространенными от долин до подгольцово-кустарникового пояса включительно, являются 23 вида.

Кроме убиквистов, в нижней части пояса эпилитно-лишайниковых сообществ ограниченно встречается Saxifraga punctata, S. spinulosa (образующая переходные формы к S. cherlerioides), Dryas crenulata и D. punctata (вероятно, образующие гибриды). Эти виды в данной местности приурочены только к горным склонам, в долинном комплексе растительности не отмечены.

Растений долинного комплекса и лесного пояса насчитывается 74 таксона, а растений лесного и подгольцово-кустарникового пояса - 11.

Таблица

Распределение сосудистых растений ресурсного резервата «Верхнеиндигирский» по высотным поясам

\begin{tabular}{|l|c|c|c|c|}
\hline \multirow{2}{*}{ Наименование таксонов } & \multicolumn{5}{|c|}{ Высотный пояс } \\
\cline { 2 - 5 } & ДК & ЛП & ПГКП & ПЭЛС \\
\hline Botrychaceae Nakai & 2 & 3 & 4 & 5 \\
\hline Botrychium lunaria (L.) Sw. & & & & \\
\hline Cystopteridaceae (Payer) Schmakov & & + & & \\
\hline Cystopteris dickieana R. Sim. & & & & \\
\hline Gymnocarpium continentale (Petrov) Pojark. & & + & & \\
\hline G. jessoense (Koidz.) Koidz. & & + & & \\
\hline
\end{tabular}


Е. Г. Николин. Высотно-зональное распределение сосудистых растений ресурсного резервата «Верхнеиндигирский» (Россия, Северо-Восточная Якутия)

\begin{tabular}{|c|c|c|c|c|}
\hline 1 & 2 & 3 & 4 & 5 \\
\hline \multicolumn{5}{|l|}{ Dryopteridaceae Ching } \\
\hline Dryopteris fragrans (L.) Schott & + & + & + & \\
\hline \multicolumn{5}{|l|}{ Woodsiaceae (Diels) Herter } \\
\hline Woodsia glabella $\mathrm{R} . \mathrm{Br}$. & & + & + & \\
\hline W. heterophylla (Turcz. ex Fomin) Schmakov & & & + & \\
\hline W. ilvensis (L.) R. Br. & & & + & \\
\hline \multicolumn{5}{|l|}{ Equisetaceae Rich. } \\
\hline Equisetum arvense L. & + & + & & \\
\hline E. fluviatile L. & + & & & \\
\hline E. palustre L. & + & 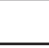 & & \\
\hline E. scirpoides Michx. & & + & & \\
\hline E. variegatum Schleich. ex Web. et Mohr & + & & & \\
\hline \multicolumn{5}{|l|}{ Huperziaceae Rothm. } \\
\hline Huperzia appressa (Desv.) A. et D. Löve & + & + & & \\
\hline H. arctica (Tolm.) Sipliv. & + & + & & \\
\hline \multicolumn{5}{|l|}{ Selaginellaceae Willk. } \\
\hline Selaginella rupestris (L.) Spring & + & + & & \\
\hline \multicolumn{5}{|l|}{ Pinaceae Spreng. ex Rudolphi } \\
\hline Larix dahurica Turcz. subsp. cajanderi (Mayr.) Dyl. & + & + & + & \\
\hline Pinus pumila (Pall.) Regel & + & + & + & + \\
\hline \multicolumn{5}{|l|}{ Cupressaceae Gray. } \\
\hline Juniperus sibirica Burgsd. & & + & + & \\
\hline \multicolumn{5}{|l|}{ Sparganiaceae Rudolphi } \\
\hline Sparganium hyperboreum Laest. & + & & & \\
\hline \multicolumn{5}{|l|}{ Potamogetonaceae Dumort. } \\
\hline Potamogeton alpinus Balb. & + & & & \\
\hline P. perfoliatus L. & + & & & \\
\hline P. praelongus Wulf. & + & & & \\
\hline $\begin{array}{l}\text { Stuckenia filiformis (Pers.) Börner (Potamogeton } \\
\text { filiformis Pers.) }\end{array}$ & + & & & \\
\hline \multicolumn{5}{|l|}{ Poaceae Barnh. (Gramineae Juss.) } \\
\hline Agrostis kudoi Honda & + & & & \\
\hline A. vinealis Schreber s.1. & + & & & \\
\hline Arctagrostis arundinacea (Trin.) Beal. & + & & & \\
\hline A. latifolia (R.Br.) Griseb. & + & + & & \\
\hline Arctophila fulva (Trin.) Anderss. & + & & & \\
\hline Beckmannia syzigachne (Steud.) Fern. & + & & & \\
\hline Bromopsis karavajevii (Tzvel.) Czer. & + & & & \\
\hline $\begin{array}{l}\text { B. pumpelliana (Scribn.) Holub (B. sibirica (Drob.) } \\
\text { Peschkova) }\end{array}$ & + & + & & \\
\hline Calamagrostis holmii Lange & + & + & & \\
\hline C. langsdorffii (Link) Trin. & + & & & \\
\hline C. lapponica (Wahlenb.) C. Hartm. & + & + & & \\
\hline C. neglecta (Ehrh.) Gaertn., Mey. et Schreb. s. str. & + & + & & \\
\hline
\end{tabular}


ВЕСТНИК БУРЯТСКОГО ГОСУДАРСТВЕННОГО УНИВЕРСИТЕТА

\begin{tabular}{|c|c|c|c|c|}
\hline 1 & 2 & 3 & 4 & 5 \\
\hline C. purpurascens $\mathrm{R} . \mathrm{Br}$. & + & & & \\
\hline C. purpurea (Trin.) Trin. s.str. & + & & & \\
\hline C. tenuis V.Vassil. & + & & & \\
\hline Deschampsia borealis (Trautv.) Roshev. & + & & & \\
\hline D. cespitosa (L.) Beauv. & + & & & \\
\hline D. submutica (Trautv.) Nikiforova & + & & & \\
\hline D. sukatschewii (Popl.) Roshev. & + & & & \\
\hline Elymus charkeviczii Probat. & + & & & \\
\hline E. kronokensis (Kom.) Tzvelev & + & & & \\
\hline E. macrourus (Turcz.) Tzvelev s.str. & + & & & \\
\hline E. pubiflorus (Roshev.) Peschkova & + & & & \\
\hline Festuca brachyphylla Schult. et Schult. fil. & + & + & & \\
\hline F. ovina L. & + & & & \\
\hline F. rubra L. & + & & & \\
\hline Hierochloe alpina (Sw.) Roem. et Schult. & & + & + & \\
\hline Hordeum jubatum L. & + & & & \\
\hline Poa angustifolia $\mathrm{L}$. & + & + & & \\
\hline P. arctica $\mathrm{R}$.Br. & + & + & & \\
\hline$P$. attenuata Trin. & + & & & \\
\hline P. botryoides (Trin. ex Griseb.) Kom. & + & . & & \\
\hline P. filiculmis Roshev. & + & + & + & \\
\hline P. glauca Vahl & + & + & + & \\
\hline P. lanata Scribn. et Merr. & + & & & \\
\hline P. malacantha Kom. & + & + & + & \\
\hline P. ochotensis Trin. & + & & & \\
\hline P. urssulensis Trin. & + & & & \\
\hline Trisetum agrostideum (Laest.) Tries. & + & + & & \\
\hline T. molle Kunth & + & & & \\
\hline T. sibiricum Rupr. subsp. litorale Rupr. ex Roshev. & + & + & & \\
\hline T. spicatum (L.) K. Richt. & + & & & \\
\hline \multicolumn{5}{|l|}{ Cyperaceae Juss. } \\
\hline Carex acuta $\mathrm{L}$. & + & & & \\
\hline C. appendiculata (Trautv. et Mey.) Kuk. & + & & & \\
\hline C. aquatilis Wahlenb. s.str. & + & & & \\
\hline C. aquatilis Wahlenb. subsp. stans (Drej.) Hult. & + & & & \\
\hline $\begin{array}{l}\text { C. bigelowii Torr. ex Schwein. subsp. arctisibirica } \\
\text { (Jurtz.) A. et D. Love }\end{array}$ & & + & + & \\
\hline $\begin{array}{l}\text { C. bigelowii Torr. ex Schwein. subsp. ensifolia } \\
\text { (Turcz. ex Gorodk.) Holub }\end{array}$ & + & + & + & \\
\hline $\begin{array}{l}\text { C. bigelowii Torr. ex Schwein. subsp. rigidioides } \\
\text { (Gorodk.) Egor. }\end{array}$ & & + & & \\
\hline C. canescens $\mathrm{L}$. & + & & & \\
\hline C. capitata $\mathrm{L}$. & + & & & \\
\hline C. chordorrhiza Ehrh. & + & & & \\
\hline
\end{tabular}


Е. Г. Николин. Высотно-зональное распределение сосудистых растений ресурсного резервата «Верхнеиндигирский» (Россия, Северо-Восточная Якутия)

\begin{tabular}{|c|c|c|c|c|}
\hline 1 & 2 & 3 & 4 & 5 \\
\hline Carex cinerascens Kuk. & + & & & \\
\hline C. eleusinoides Turcz. ex Kunth & + & & & \\
\hline C. fuscidula V. Krecz. ex Egor. & & + & & \\
\hline C. globularis $\mathrm{L}$. & + & + & & \\
\hline C. gynocrates Wormsk. & + & & & \\
\hline C. holostoma Drej. & + & & & \\
\hline C. jacutica V. Krecz. & + & & & \\
\hline C. juncella (Fries) Th. Fries & + & & & \\
\hline C. $\operatorname{limosa} \mathrm{L}$. & + & & & \\
\hline C. loliacea $\mathrm{L}$. & + & & & \\
\hline C. lugens H.T. Holm. & + & + & & \\
\hline C. media R.Br. & + & & & \\
\hline C. melanocarpa Cham. ex Trautv. & & + & + & \\
\hline C. minuta Franch. & + & & & \\
\hline C. norvegica Retz. & & + & & \\
\hline C. reptabunda (Trautv.) V. Krecz. & + & & & \\
\hline C. rostrata Stokes & + & & & \\
\hline C. rotundata Wahlenb. & + & & & \\
\hline C. saxatilis L. s.str. & + & & & \\
\hline C. saxatilis L. subsp. laxa (Trautv.) Kalela & + & & & \\
\hline C. soczaveana Gorodk. & + & & & \\
\hline C. stylosa C.A. Mey & + & & & \\
\hline C. tenuiflora Wahlenb. & + & & & \\
\hline $\begin{array}{l}\text { C. vaginata Tausch. subsp. quasivaginata (C.B. } \\
\text { Clarke) Malyschev }\end{array}$ & + & & & \\
\hline C. vanheurckii Muell. ex Arg. & + & & & \\
\hline C. williamsii Britt. & + & & & \\
\hline Eleocharis acicularis (L.) Roem. et Schult. & + & & & \\
\hline Eriophorum angustifolium Honck. & + & & & \\
\hline E. callitrix Cham. ex C.A. Mey. & + & & & \\
\hline E. humile Turcz. et Steud. & + & & & \\
\hline E. russeolum Fries subsp. leiocarpum Novoselova & + & & & \\
\hline E. scheuchzeri Hoppe & + & & & \\
\hline E. scheuchzeri Hoppe subsp. arcticum Novoselova & + & & & \\
\hline E. tolmatchevii Novoselova & + & & & \\
\hline E. vaginatum L. s.str. & + & + & & \\
\hline Kreczetoviczia caespitosa $(\mathrm{L}$.$) Tzvelev$ & + & & & \\
\hline Scirpus maximowiczii C. B. Clarke & + & & & \\
\hline \multicolumn{5}{|l|}{ Juncaceae Juss. } \\
\hline Juncus alpinoarticulatus Chaix & + & & & \\
\hline J. arcticus Willd. & + & & & \\
\hline $\begin{array}{l}\text { J. articulatus L. subsp. limosus (Worosch.) Worosch. } \\
\text { (J. turczaninowii (Busch.) Freyn) }\end{array}$ & + & & & \\
\hline J. castaneus Smith & + & & & \\
\hline
\end{tabular}


ВЕСТНИК БУРЯТСКОГО ГОСУДАРСТВЕННОГО УНИВЕРСИТЕТА

\begin{tabular}{|c|c|c|c|c|}
\hline 1 & 2 & 3 & 4 & 5 \\
\hline J. triglumis L. & + & & & \\
\hline Luzula confusa Lindeb. & & & + & \\
\hline L. multiflora (Ehrh. et Retz.) Lej. s.l. & + & + & & \\
\hline L. nivalis (Laest.) Spreng. & + & + & & \\
\hline L. rufescens Fisch. ex E.Mey. & + & & & \\
\hline \multicolumn{5}{|l|}{ Melanthiaceae Batsch ex Borch. } \\
\hline Tofieldia coccinea Richards. & + & + & + & \\
\hline \multicolumn{5}{|l|}{ Alliaceae Borch. } \\
\hline Allium schoenoprasum L. & + & & & \\
\hline A. strictum Schrad. & + & & & \\
\hline \multicolumn{5}{|l|}{ Orchidaceae Mirb. } \\
\hline Coeloglossum viride (L.) C. Hartm. & + & & & \\
\hline Gymnadenia conopsea (L.) R.Br. (?) & + & & & \\
\hline \multicolumn{5}{|l|}{ Salicaceae Mirb. } \\
\hline Chosenia arbutifolia (Pall.) A.K. Skvortsov & + & . & & \\
\hline Populus suaveolens Fisch. & + & + & & \\
\hline Salix alaxensis Coville & + & & & \\
\hline S. bebbiana Sarg. & + & + & & \\
\hline S. boganidensis Trautv. & + & & & \\
\hline S. brachypoda (Trautv. et C.A. Mey.) Kom. & + & + & & \\
\hline S. dasyclados Wimm. & + & + & & \\
\hline S. divaricata Pall. & + & + & & \\
\hline S. dschugdshurica A.K. Skvortsov & + & & & \\
\hline S. fuscescens Andersson & + & & & \\
\hline S. glauca L. & + & & & \\
\hline S. hastata L. & + & . & & \\
\hline S. lanata L. & & + & & \\
\hline S. myrtilloides L. & + & + & & \\
\hline S. pseudopentandra (Flod.) Flod. & + & & & \\
\hline S. pulchra Cham. & + & + & & \\
\hline S. pyrolifolia Ledeb. & + & 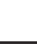 & & \\
\hline S. recurvigemmis A.K. Skvortsov & & + & & \\
\hline S. rorida Laksch. & + & & & \\
\hline S. saxatilis Turcz. ex Ledeb. & + & + & & \\
\hline S. schwerinii E.L. Wolf. & + & & & \\
\hline S. tschuktschorum A.K. Skvortsov & + & + & + & + \\
\hline $\begin{array}{l}\text { S. ustnerensis (Bolsch.) Baikov ex A.V. Grebenyuk et } \\
\text { Czepinoga }\end{array}$ & + & + & & \\
\hline \multicolumn{5}{|l|}{ Betulaceae S. F. Gray } \\
\hline Betula divaricata Ledeb. & + & + & + & \\
\hline B. nana L. subsp. exilis (Sukacz.) Hult. & + & & & \\
\hline Duschekia fruticosa (Rupr.) Pouzar & + & + & + & \\
\hline \multicolumn{5}{|l|}{ Urticaceae Juss. } \\
\hline Urtica sondenii (Simm.) Avror. ex Geltman & & + & & \\
\hline
\end{tabular}


Е. Г. Николин. Высотно-зональное распределение сосудистых растений ресурсного резервата «Верхнеиндигирский» (Россия, Северо-Восточная Якутия)

\begin{tabular}{|c|c|c|c|c|}
\hline 1 & 2 & 3 & 4 & 5 \\
\hline \multicolumn{5}{|l|}{ Polygonaceae Juss. } \\
\hline Acetosella aureostigmatica Kom. & + & & & \\
\hline A. vulgaris L. & + & & & \\
\hline Aconogonon tripterocarpum (A.Grey) Hara & + & + & & \\
\hline Bistorta vivipara (L.) Delabre & + & + & & \\
\hline Oxyria digyna (L.) Hill & + & + & + & \\
\hline Polygonum aviculare L. & + & & & \\
\hline P. humifusum Merk ex C. Koch & + & & & \\
\hline Rheum compactum L. & + & + & & \\
\hline \multicolumn{5}{|l|}{ Portulacaceae Juss. } \\
\hline Claytonia acutifolia Pall. ex Schult. & + & & & \\
\hline \multicolumn{5}{|l|}{ Caryophyllaceae Juss. } \\
\hline Cerastium beeringianum Cham. et Schltdl. s.l. & + & + & & \\
\hline Dianthus repens Willd. & + & & & \\
\hline Gastrolychnis uniflora (Ledeb.) Tzvel. & + & & & \\
\hline G. violascens Tolm. & + & & & \\
\hline Moehringia lateriflora (L.) Fenzl & + & & & \\
\hline Sagina saginoides (L.) Karst. & + & & & \\
\hline Silene amoena L. (S. repens Patrin) & + & & & \\
\hline Stellaria altimontana N.S. Pawlova & + & & & \\
\hline S. crassifolia Ehrh. & + & & & \\
\hline S. dahurica Willd. ex D. F. K. Schltdl. & + & & & \\
\hline S. edwardsii R. Br. ex Rich. & + & + & & \\
\hline S. fischerana Ser. & + & + & & \\
\hline S. longifolia Muehl. ex Willd. & + & + & & \\
\hline S. monantha Hult. & + & & & \\
\hline S. palustris Retz. s.1. & + & & & \\
\hline \multicolumn{5}{|l|}{ Ranunculaceae Juss. } \\
\hline Aconitum productum Reichenb. & + & + & & \\
\hline Caltha arctica $\mathrm{R}$. Br. & + & & & \\
\hline C. palustris L. s.str. & + & & & \\
\hline C. palustris L. subsp. membranacea (Turcz.) Hult. & + & + & & \\
\hline Coptidium lapponicum (L.) Tzvel. & + & & & \\
\hline Pulsatilla davurica (Fisch.) Sprengel & + & & & \\
\hline P. patens (L.) Miller s.1. (P. angustifolia Turcz. - ?) & + & + & & \\
\hline Ranunculus gmelinii DC. & + & & & \\
\hline R. grayi Britt. & & + & + & \\
\hline R. monophyllus Ovcz. & + & & & \\
\hline R. reptans L. & + & & & \\
\hline $\begin{array}{l}\text { R. trichophyllus Chaix (Batrachium trichophyllum } \\
\text { (Chaix) Bosch) }\end{array}$ & + & & & \\
\hline \multicolumn{5}{|l|}{ Papaveraceae Juss. } \\
\hline Papaver minutiflorum Tolm. & + & & & \\
\hline P. nivale Tolm. & + & + & & \\
\hline
\end{tabular}


ВЕСТНИК БУРЯТСКОГО ГОСУДАРСТВЕННОГО УНИВЕРСИТЕТА

\begin{tabular}{|c|c|c|c|c|}
\hline 1 & 2 & 3 & 4 & 5 \\
\hline P. pulvinatum Tolm. & + & & & \\
\hline \multicolumn{5}{|l|}{ Brassicaceae Burnett (Cruciferae Juss.) } \\
\hline Arabidopsis septentrionalis (N. Busch) V.I. Dorof. & + & & & \\
\hline A. umbrosa (Turcz. ex Steud.) V.I. Dorof. & & + & & \\
\hline Barbarea orthoceras Ledeb. & + & & & \\
\hline Cardamine bellidifolia $\mathrm{L}$. & + & + & + & \\
\hline C. nymanii Gand. (C. pratensis L. s.1.) & + & & & \\
\hline Draba cinerea Adams & + & + & & \\
\hline D. hirta L. & & + & & \\
\hline D. juvenilis Kom. & + & & & \\
\hline D. nemorosa L. & + & & & \\
\hline D. sambukii Tolm. & + & + & & \\
\hline $\begin{array}{l}\text { Erysimum boreale C.A. Mey. (E. marschallianum } \\
\text { Andrz.) }\end{array}$ & + & & & \\
\hline \multicolumn{5}{|l|}{ Droseraceae Salisb. } \\
\hline Drosera anglica Huds. & + & & & \\
\hline D. rotundifolia $\mathrm{L}$. & + & & & \\
\hline \multicolumn{5}{|l|}{ Crassulaceae J. St.-Hil. } \\
\hline $\begin{array}{l}\text { Hylotelephium sukaczevii (Maxim.) S. Gontch. et A. } \\
\text { V. Grebenjuk (Sedum sukaczevii Maximova) }\end{array}$ & + & & & \\
\hline Orostachys spinosa (L.) C.A. Mey. & & + & & \\
\hline \multicolumn{5}{|l|}{ Saxifragaceae Juss. } \\
\hline $\begin{array}{l}\text { Chrysosplenium alternifolium L. subsp. sibiricum } \\
\text { (Ser. ex DC.) Hult. }\end{array}$ & + & + & & \\
\hline C. tetrandrum (Lund. ex Malmgr.) Th. Fries & + & & & \\
\hline Saxifraga cernua $\mathrm{L}$. & + & + & & \\
\hline S. hieracifolia Waldst. et Kit. & + & & & \\
\hline S. hyperborea R. Br. & & + & + & \\
\hline S. ledebouriana Holub (S. multiflora Ledeb.) & & + & + & \\
\hline S. nelsoniana D. Don & + & + & & \\
\hline S. nivalis L. & + & + & & \\
\hline S. punctata L. & & + & + & + \\
\hline S. radiata Small & + & + & & \\
\hline S. redofskyi Adams & + & + & & \\
\hline S. spinulosa Adams & & + & + & + \\
\hline \multicolumn{5}{|l|}{ Parnassiaceae Martinov } \\
\hline Parnassia palustris L. & + & & & \\
\hline \multicolumn{5}{|l|}{ Grossulariceae DC. } \\
\hline Ribes dikuscha Fisch. ex Turcz. & + & & & \\
\hline R. fragrans Pall. & + & + & + & \\
\hline R. triste Pall. & + & + & + & \\
\hline \multicolumn{5}{|l|}{ Rosaceae Juss. } \\
\hline Comarum palustre L. & + & & & \\
\hline Dryas crenulata Juz. & & + & + & + \\
\hline
\end{tabular}


Е. Г. Николин. Высотно-зональное распределение сосудистых растений ресурсного резервата «Верхнеиндигирский» (Россия, Северо-Восточная Якутия)

\begin{tabular}{|c|c|c|c|c|}
\hline 1 & 2 & 3 & 4 & 5 \\
\hline D. grandis Juz. & + & + & & \\
\hline D. punctata Juz. & & + & + & + \\
\hline Potentilla arenosa (Turcz.) Juz. & + & + & & \\
\hline $\begin{array}{l}\text { P. fruticosa L. (Pentaphylloides fruticosa (L.) O. } \\
\text { Schwarz) }\end{array}$ & + & + & & \\
\hline P. inquinans Turcz. & + & + & + & \\
\hline P. nivea L. (incl. P. crebridens Juz.) & + & + & + & \\
\hline P. pensylvanica L. & + & & & \\
\hline P. stipularis L. & + & & & \\
\hline Rosa acicularis Lindl. & + & + & & \\
\hline Rubus arcticus L. & + & & & \\
\hline R. chamaemorus L. & + & + & & \\
\hline R. sachalinensis Levl. & + & + & & \\
\hline Sanguisorba officinalis L. & + & 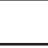 & & \\
\hline Sorbaria grandiflora (Swiit) Maxim. & + & + & + & \\
\hline \multicolumn{5}{|l|}{ Fabaceae Lindl. (Leguminosae Juss.) } \\
\hline Astragalus alpinus L. & + & . & & \\
\hline A. frigidus (L.) A. Gray & + & + & & \\
\hline A. schelichowii Turcz. & + & 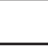 & & \\
\hline A. vallicola Gontsch. & & + & & \\
\hline Hedysarum arcticum B. Fedtsch. & + & + & & \\
\hline H. branthii Trautv. et C.A. Mey. & + & + & & \\
\hline Oxytropis adamsiana (Trautv.) Jurtz. s.l. & + & & & \\
\hline O. leucantha (Pall.) Bunge s.l. & + & & & \\
\hline O. ochotensis Bunge & + & & & \\
\hline O. subnutans (Jurtz.) Jurtz. & + & & & \\
\hline O. vassilczenkoi Jurtz. s.str. & + & & & \\
\hline \multicolumn{5}{|l|}{ Callitrichaceae Link } \\
\hline Callitriche palustris L. & + & & & \\
\hline \multicolumn{5}{|l|}{ Empetraceae Hook. et Lindl. } \\
\hline Empetrum nigrum L. s.1. & + & + & + & \\
\hline \multicolumn{5}{|l|}{ Onagraceae Juss. } \\
\hline Chamaenerion angustifolium (L.) Scop. & + & + & & \\
\hline C. latifolium $(\mathrm{L})$ Th.Fries et Lange & + & + & & \\
\hline Epilobium alpinum L. & + & & & \\
\hline E. davuricum Fisch. ex Hornem. & + & & & \\
\hline \multicolumn{5}{|l|}{ Haloragaceae R. Br. } \\
\hline Myriophyllum verticillatum L. & + & & & \\
\hline \multicolumn{5}{|l|}{ Hippuridaceae Vest } \\
\hline Hippuris vulgaris L. & + & & & \\
\hline \multicolumn{5}{|l|}{ Apiaceae Lindl. (Umbelliferae Juss.) } \\
\hline Cicuta virosa L. & + & & & \\
\hline $\begin{array}{l}\text { Phlojodicarpus villosus (Turcz. ex Fisch. et C. A. } \\
\text { Mey.) Ledeb. }\end{array}$ & & + & & \\
\hline
\end{tabular}


ВЕСТНИК БУРЯТСКОГО ГОСУДАРСТВЕННОГО УНИВЕРСИТЕТА

\begin{tabular}{|c|c|c|c|c|}
\hline 1 & 2 & 3 & 4 & 5 \\
\hline \multicolumn{5}{|l|}{ Pyrolaceae Dumort. } \\
\hline Orthilia obtusata (Turcz.) Jutrz. & + & + & & \\
\hline O. secunda (L.) House & + & + & & \\
\hline Pyrola asarifolia Michx. & + & + & & \\
\hline \multicolumn{5}{|l|}{ Ericaceae Juss. } \\
\hline Andromeda polifolia L. & + & + & & \\
\hline Arctous erythrocarpa Small. & + & & & \\
\hline Cassiope ericoides (Pall.) D. Don. & + & + & + & + \\
\hline C. tetragona (L.) D. Don & & + & + & \\
\hline Chamaedaphne calyculata (L.) Moench & + & + & & \\
\hline Ledum palustre L. subsp. decumbens (Ait.) Hult. & + & + & + & + \\
\hline L. palustre L. var. angustum N. Busch. & + & + & + & \\
\hline L. palustre L. var. dilatatum Wahlenb. & & + & & \\
\hline Oxycoccus microcarpus Turcz. ex Rupr. & + & + & & \\
\hline Rhododendron lapponicum (L.) Wahlenb. s.str. & + & + & & \\
\hline $\begin{array}{l}\text { R. lapponicum (L.) Wahlenb. subsp. parvifolium } \\
\text { (Adams) Malyschev }\end{array}$ & + & + & & \\
\hline R. redowskianum Maxim. & & + & + & \\
\hline $\begin{array}{l}\text { Vaccinium uliginosum L. subsp. microphyllum } \\
\text { (Lange) Tolm. }\end{array}$ & + & + & + & \\
\hline V. vitis-idaea L. s.str. & + & + & & \\
\hline V. vitis-idaea L. subsp. minus (Lodd.) Hult. & + & + & + & \\
\hline \multicolumn{5}{|l|}{ Primulaceae Batsch ex Borkh } \\
\hline Androsace septentrionalis L. & + & + & & \\
\hline \multicolumn{5}{|l|}{ Gentianaceae Juss. } \\
\hline Ciminalis aquatica L. & + & & & \\
\hline \multicolumn{5}{|l|}{ Menyanthaceae Dumort. } \\
\hline Menyanthes trifoliata L. & + & & & \\
\hline \multicolumn{5}{|l|}{ Polemoniaceae Juss. } \\
\hline Polemonium pulchellum Bunge & + & + & & \\
\hline P. coeruleum L. s.1. & + & & & \\
\hline \multicolumn{5}{|l|}{ Lamiaceae Martinov (Labitae Juss.) } \\
\hline Dracocephalum palmatum Steph. & + & + & + & \\
\hline Thymus bituminosus Klokov (T. pavlovii Serg.) & & + & & \\
\hline \multicolumn{5}{|l|}{ Scrophulariaceae Juss. } \\
\hline Castilleja rubra (Drob.) Rebr. & + & & & \\
\hline Euphrasia jacutica Juz. & + & & & \\
\hline Pedicularis kolymensis Khokhr. & + & & & \\
\hline P. labradorica Wirsing & + & + & & \\
\hline P. lapponica L. & & + & & \\
\hline P. sceptrum-carolinum L. & + & & & \\
\hline $\begin{array}{l}\text { P. sudetica Willd. subsp. gymnostachya (Trautv.) } \\
\text { Jurtz. et Petrovsky }\end{array}$ & + & & & \\
\hline P. sudetica Willd. subsp. interioroides Hult. & + & & & \\
\hline
\end{tabular}


Е. Г. Николин. Высотно-зональное распределение сосудистых растений ресурсного резервата «Верхнеиндигирский» (Россия, Северо-Восточная Якутия)

\begin{tabular}{|c|c|c|c|c|}
\hline 1 & 2 & 3 & 4 & 5 \\
\hline \multicolumn{5}{|l|}{ Orobanchaceae Vent. } \\
\hline Boschniakia rossica (Cham. et Schlecht.) B. Fedtsch. & & + & & \\
\hline \multicolumn{5}{|l|}{ Lentibulariaceae Rich. } \\
\hline Pinguicula spathulata Ledeb. & + & & & \\
\hline P. villosa $\mathrm{L}$. & + & + & & \\
\hline Utricularia intermedia Hayne & + & & & \\
\hline U. macrorhiza Leconte & + & & & \\
\hline \multicolumn{5}{|l|}{ Rubiaceae Juss. } \\
\hline Galium boreale L. & + & & & \\
\hline G. brandegei A. Gray & + & & & \\
\hline G. densiflorum Ledeb. & + & & & \\
\hline G. palustre L. & + & & & \\
\hline G. ruthenicum Willd. & + & & & \\
\hline \multicolumn{5}{|l|}{ Caprifoliaceae Juss. } \\
\hline Linnaea borealis L. & + & & & \\
\hline \multicolumn{5}{|l|}{ Adoxaceae E. Mey. } \\
\hline Adoxa moschatellina L. & + & & & \\
\hline \multicolumn{5}{|l|}{ Valerianaceae Batsch } \\
\hline Valeriana capitata Pall. ex Link. & + & + & & \\
\hline \multicolumn{5}{|l|}{ Campanulaceae Juss. } \\
\hline Campanula rotundifolia $\mathrm{L}$. & + & + & + & \\
\hline \multicolumn{5}{|l|}{$\begin{array}{l}\text { Asteraceae Bercht. et G. Presl. (Compositae Gise- } \\
\text { ke) }\end{array}$} \\
\hline Achillea millefolium $\mathrm{L}$. & + & & & \\
\hline Arnica iljinii (Maguire) Iljin & + & + & & \\
\hline Artemisia bargusinensis Spreng. & + & & & \\
\hline A. borealis Pall. & + & & & \\
\hline A. kruhsiana Besser subsp. condensata Korobkov & + & + & + & \\
\hline A. lagocephala (Fisch. ex Besser) DC. & + & + & + & \\
\hline A. leucophylla (Turcz. ex Besser) Clarke & + & & & \\
\hline A. subarctica Krasch. & + & & & \\
\hline A. tanacetifolia L. & + & & & \\
\hline Aster alpinus L. & + & & & \\
\hline $\begin{array}{l}\text { Crepis chrysantha (Ledeb.) Turcz. subsp. minor } \\
\text { (Ledeb.) Lomonosova }\end{array}$ & & & + & \\
\hline C. gmelinii (L.) Tausch & + & & & \\
\hline C. jacutica Lomonosova & & + & & \\
\hline Erigeron acris L. & + & & & \\
\hline $\begin{array}{l}\text { E. uniflorus L. subsp. eriocalyx (Ledeb.) A. et D. } \\
\text { Love }\end{array}$ & & + & + & \\
\hline $\begin{array}{l}\text { Mulgedium sibiricum Cass. ex Less. (Lactuca sibirica } \\
\text { (L.) Maxim.) }\end{array}$ & + & + & & \\
\hline Petasites frigidus (L.) Fries & + & & & \\
\hline P. sibiricus (J.F. Gmel.) Dingwall. & + & & & \\
\hline
\end{tabular}




\begin{tabular}{|l|c|c|c|c|}
\hline \multicolumn{1}{|c|}{1} & 2 & 3 & 4 & 5 \\
\hline Saussurea tilesii (Ledeb.) Ledeb. & & & + & \\
\hline $\begin{array}{l}\text { Tanacetum vulgare L. subsp. boreale (Fisch. ex DC.) } \\
\text { A. et D. Love }\end{array}$ & + & & & \\
\hline Taraxacum arcticum (Trautv.) Dahlst. & & + & & \\
\hline T. ceratophorum (Ledeb.) DC. & + & & & \\
\hline T. kolymense Khokhr. & + & & & \\
\hline T. lateritum Dahlst. & + & & & \\
\hline T. longicorne Dahlst. & + & & & \\
\hline Teрhroseris subdentata (Вunge) Ноlub & + & & & \\
\hline Всего видов, подвидов и разновидностей & 292 & 139 & 47 & 8 \\
\hline
\end{tabular}

Примечание. Сокращены названия высотных поясов: ДК - долинный комплекс растительности, ЛП - лесной пояс, ПГКП - подгольцово-кустарниковый пояс, ПЭЛС - пояс эпилитно-лишайниковых сообществ.

Заключение. Структура флоры высотных поясов и комплекса долинной растительности ресурсного резервата «Верхнеиндигирский» в целом аналогична высотно-зональному распределению видов в системе Верхоянского хребта. Но геграфическое положение этой части Оймяконского нагорья связано с более суровыми природно-климатическими условиями. Этим обусловлено слабое развитие тундровой растительности, редукция соответствующего высотного пояса и, как следствие пониженное разнообразие флоры всех высотных поясов. Соответственно, долевое участие сосудистых растений, находящих убежище в долинах горных рек, здесь неколько увеличено.

\section{Благодарности}

Работа выполнена в рамках Государственного задания ИБПК СО РАН «Фундаментальные и прикладные аспекты изучения разнообразия растительного мира Северной и Центральной Якутии». Регистрационный номер: АААА-А17-117020110056-0 и по программам НИР Министерства охраны природы РС(Я): «Составление кадастра ресурсных резерватов Республики Саха (Якутия)» и «Обследование великих озер Якутии».

Выражаю глубокую признательность за тестирование образцов гербария А. А. Боброву, В. И. Дорофееву, А. А. Коробкову, В. В. Петровскому, В. В. Якубову.

\section{Литература}

1. Куваев В. Б. Флора субарктических гор Евразии и высотное распределение ее видов. М.: Товарищество науч. изд. КМК, 2006. 568 с.

2. Николин Е. Г. Общие закономерности высотно-широтного распределения флоры Верхоянского хребта // Почвы и растительный мир горных территорий. М.: КМК, 2009а. C. 235-239.

3. Николин Е. Г. Таксономические спектры флоры Верхоянского хребта // Ботанические исследования на Урале: материалы конференции, посвященной памяти П. Л. Горчаковского. Пермь: Пермский гос. универ., 2009б. С. 250-255.

4. Николин Е. Г. Конспект флоры Верхоянского хребта. Новосибирск: Наука, 2013. 248 с. 5. Николин Е. Г. Локальные флоры ресурсного резервата «Верхнеиндигирский» СевероВосточная Якутия // Бот. журн. 2020. Т. 105, № 7. С. 627-645. 
Е. Г. Николин. Высотно-зональное распределение сосудистых растений ресурсного резервата «Верхнеиндигирский» (Россия, Северо-Восточная Якутия)

6. Николин Е.Г., Троева Е.И. Некоторые подходы к выделению высотных поясов растительности в горах Северо-Восточной Азии // Известия Самарского научного центра РАН. 2012. Т. 14, № 1 (4). С. 1084-1087.

7. Осадчий В. Г. Тайна Лабынкыра разгадана? // Турист. 2019. Вып. 1. С. 20-23.

8. Толмачев А. И. К методике сравнительно-флористического исследования. Понятие о флоре в сравнительной флористике // Журн. РБО. 1931. № 16(1). С. 111-124.

9. Толмачев А.И. О некоторых количественных соотношениях во флорах земного шара. // Вестник ЛГУ. Сер. биол. 1970. Вып. 15. С. 62-74.

10. Толмачев А. И. Методы сравнительной флористики и проблемы флорогенеза. Новосибирск: Наука, 1986. 196 с.

11. Юрцев Б. А. Флора Сунтар-Хаята. Л.: Наука, 1968. 236 с.

\section{ALTITUDINAL ZONATION OF VASCULAR PLANTS \\ OF "VERHNEINDIGIRSKIY" RESOURCE RESERVE \\ (RUSSIA, NORTH-EASTERN YAKUTIA)}

\section{E. G. Nikolin}

\section{Evgeniy G. Nikolin}

Dr. Sci. (Biol.), Chief Researcher, Institute for Biological Problems of Cryolithozone YaSC SB RAS

41 Lenina St., Yakutsk 677891, Russia

enikolin@yandex.ru

Abstract. «Verkhneindigirsky» resource reserve is located on the territory of the Russian Federation, in Oymyakon Highland, near the border of Yakutia, Magadan Oblast and the north of Khabarovsk Krai. Altitude interval marks from 850 to 1200 (1700) m above sea level. The research area is located in the extreme climate of the North pole, where winter air temperatures reaches $-65-70^{\circ} \mathrm{C}$, and the solid thickness of permafrost is $400-700 \mathrm{~m}$. Vegetation is characterized by altitudinal belts: forest, subgoltsy shrubs, epilithic-lichen communities and the complex of valley vegetation. Mountain-tundra vegetation is limited, it is not presented as a separate belt and usually is included in the structure of other vegetation belts. The vast majority of species $(292$, or $87 \%$ ) are concentrated in the valley vegetation complex. On the mountain slopes the diversity of flora is greatly reduced: in the forest belt - 139 species (41\%), in the subgoltsy shrubs belt - 47 species (14\%), and in the lower part of the epilithiclichen belt - only 8 species $(2 \%)$. In general, the distribution of flora of the resource reserve by altitudinal belts corresponds to that in the near-located system of Verkhoyansky Ridge. However, the proportion of plants in the valley complex is increased compared to the plants on mountain slopes, and there are no components of the tundra belt due to the more severe natural and climatic conditions of the investigated territory.

Keywords: North-East Yakutia; "Verkhneindigirsky" resource reserve; Labynkyr Lake; altitudinal zonation of vegetation; vascular plants; local flora; species.

Статья поступила в редакиию 15.10.20; одобрена после рещензирования 07.12.20; принята к публикации 25.01.2021. 